\title{
Cardiac hypertrophy is stimulated by altered training intensity and correlates with autophagy modulation in male Wistar rats
}

Julia Windi Gunadi ${ }^{*}$ D, Vita Murniati Tarawan², Iwan Setiawan², Ronny Lesmana ${ }^{2,3,4}$, Roro Wahyudianingsih ${ }^{5}$ and Unang Supratman ${ }^{6}$

\begin{abstract}
Background: The mechanism for cardiac hypertrophy process that would be a benefit for improvement of cardiovascular endurance needed to be investigated throughly. Specific intensity of training may play a role for homeostasis process in cardiac during training. In the present study, we examine the effect of different intensity of treadmill training on cardiac hypertrophy process and autophagy related gene expression in male wistar rats.
\end{abstract}

Methods: Three different intensities of treadmill training were conducted on 15 male wistar rats (Low Intensity: 10 m/ minute, Moderate Intensity: 20 m/minute, and High Intensity: 30 m/minute) compared to 5 sedentary rats as control. Training duration was 30 min per day, frequency was 5 days per week, during 8 weeks period. Heart weight and heart weight/body weight ratio were measured after the experiments. Left ventricle myocardium was taken for microscopic analysis with HE staining. mRNA was extracted from left ventricle myocardium for examining aMHC and autophagy related gene expression (PIK3CA, mTOR, LC3, p62) using semi quantitative PCR.

Results: We observed that altered training intensity might stimulate cardiac hypertrophy process. $\mathrm{Ml}$ and $\mathrm{HI}$ training increased heart weight and heart weight/body weight ratio. This finding is supported by microscopic result in which cardiac hypertrophy was found in $\mathrm{Ml}$ and $\mathrm{HI}$, with focal fibrosis in $\mathrm{HI}$, and increased aMHC gene expression in $\mathrm{Ml}(p<$ 0.05 ) and $\mathrm{HI}(p=0.076)$. We also observed decreased PIK3CA ( $L$ I 0.8 fold, MI 0.9 fold), mTOR (LI 0.9 fold, MI 0.9 fold), LC3 (LI 0.9 fold, Ml 0.8 fold, HI 0.8 fold), and p62 (LI 0.8 fold, MI 0.9 fold) compared to control. Interestingly, we found increased mTOR (HI 1.1 fold) and p62 (HI 1.1 fold) compared to control.

Conclusion: Training with different intensity creates different cardiac hypertrophy process based on heart weight and heart weight/body weight ratio, microscopic examination and autophagy related gene expression.

Keywords: Autophagy, Training, Cardiac hypertrophy, aMHC, PIK3CA, mTOR, LC3, p62

\section{Background}

Cardiovascular fitness can be improved by regular training. A well-trained athlete can achieve a cardiac output double that of a sedentary person, in part because training causes cardiac hypertrophy, which is defined as enlargement of the heart [1]. Training stimulates increase of cardiac performance, which is initiated by anatomical

\footnotetext{
* Correspondence: juliawindig@gmail.com

'Department of Physiology, Faculty of Medicine, Maranatha Christian University, Bandung, Indonesia

Full list of author information is available at the end of the article
}

tissue rearrangement, followed by optimizing its function, called as physiological cardiac hypertrophy. In the other side, pathological cardiac hypertrophy indicated by anatomical change like fiber replacements, loss of cardiomyocytes, lead to heart failure and sudden death [2,3].

Cardiac hypertrophy is initiated in order to follow process of physiology. Physiological cardiac hypertrophy can be defined as a benign increase in heart mass with morphological alteration, which represents a physiological adaptation to chronic training. There has been some questions about whether high intensity training could develop pathological

(c) The Author(s). 2019 Open Access This article is distributed under the terms of the Creative Commons Attribution 4.0 International License (http://creativecommons.org/licenses/by/4.0/), which permits unrestricted use, distribution, and reproduction in any medium, provided you give appropriate credit to the original author(s) and the source, provide a link to the Creative Commons license, and indicate if changes were made. The Creative Commons Public Domain Dedication waiver (http://creativecommons.org/publicdomain/zero/1.0/) applies to the data made available in this article, unless otherwise stated. 
cardiac hypertrophy, but there is no evidence showing remodeling due to training leads to long-term cardiac disease progression, cardiovascular disability, or sudden cardiac death $[4,5]$. Furthermore, left ventricle hypertrophy after long term training is reversible following detraining $[6,7]$, so it can be concluded that physiological cardiac hypertrophy induced by training is a benign adaptation [2].

Sustained training increased the oxygen demand of the muscles. Whether the demand is met depends mainly on the adequacy of cardiac output and proper functioning of the respiratory system. After several weeks of training, cardiac output is increased, which also increases the maximal rate of oxygen delivery to tissues $/ \mathrm{VO}_{2} \max$ [1]. Many studies confirmed that cardiac adaptations to training are closely related to increased $\mathrm{VO}_{2}$ max. However, little is known about cardiac hypertrophy related to different intensity, especially at molecular level. The question remains about how much training is optimal for cardiovascular benefit and what molecular mechanism for cardiac hypertrophy process that would be a benefit for improvement of cardiovascular endurance $[8,9]$.

Genetic mouse models have provided substantial evidence about molecular pathway that regulates physiological cardiac growth. Signaling cascades responsible for mediating physiological cardiac hypertrophy is IGF1phosphoinositide 3-kinase (PI3KCA/p110 $\alpha$ )-Akt-mTOR pathway [2, 4]. mTOR is an atypical serine/threonine protein kinase that affects gene transcription, protein translation, regulation of cell growth, apoptosis, and autophagy [10]. mTOR is encoded by a single gene in mammals and represents the catalytic subunit of mTORC1, which is the main regulator of cellular growth in response to different environmental and intracellular conditions. It promotes anabolic process such as protein synthesis while inhibits catabolic pathways such as autophagy in cardiovascular system $[11,12]$.
Autophagy is a conserved mammalian catabolic process by which unwanted cellular cargos and dysfunctional organelles are discarded in a lysosome-dependent manner [13]. Autophagy in cardiovascular system can be referred as cardiac autophagy. Endurance training may alter cardiac autophagy that leads to a protective role against hypoxia and ischemia-reperfusion injury [14, 15]. Recent studies have shown that acute and chronic endurance training enhances autophagy in cardiac muscles [16-19]. A proper regulation of cardiac autophagy is important because a chronic upregulation of cardiac autophagy may induce a detrimental effect.

In cardiac hypertrophy, cardiac myocytes rearrangement by different intensity of chronic endurance training may strongly involves autophagy. However, the effect of different intensity of chronic training on cardiac autophagy remains unclear. The objective of this study is to examine the effect of different intensity of treadmill training on cardiac hypertrophy process and autophagy related gene expression in male Wistar rats. In the present study, we postulate that different intensity of training creates a different response in cardiac hypertrophy and correlates with cardiac autophagy.

\section{Methods}

\section{Animals}

We obtained 20 male wistar rats aged 8 weeks, weighed $200 \pm 50 \mathrm{~g}$, from PT. Biofarma, Bandung, Indonesia. The rats were placed in a standardized cage (5 rats in each cage), given pellet rodent diet (normal Chow Diet) and water ad libitum every day. The dark and light cycle environment were maintained within $12 \mathrm{~h}$ with stable humidity and temperature around $\pm 22-24{ }^{\circ} \mathrm{C}$. Adaptation to environment conducted in 2 weeks period, food and water provided ad libitum. The procedures for treatment of the animals were conducted according to the guide for the

Table 1 Primers used for Semi quantitative-PCR analysis

\begin{tabular}{|c|c|c|c|c|c|}
\hline Gene Symbol & $\begin{array}{l}\left.\text { Primer Sequence ( } 5^{\prime} \text { to } 3^{\prime}\right) \\
\text { Upper strand: sense } \\
\text { Lower strand: antisense }\end{array}$ & $\begin{array}{l}\text { Product } \\
\text { Size } \\
\text { (bp) }\end{array}$ & $\begin{array}{l}\text { Annealing } \\
\left({ }^{\circ} \mathrm{C}\right)\end{array}$ & Cycle & References \\
\hline \multirow[t]{2}{*}{$\overline{\mathrm{aMHC}}$} & GAGCAGGAGCTGATCGAGAC & 151 & 60 & 35 & [26] \\
\hline & СCTCTGCGTTCCTACACTCC & & & & \\
\hline \multirow[t]{2}{*}{ PIK3CA } & ACCTCAGGCTTGAAGAGTGTCG & 137 & 59 & 35 & [27] \\
\hline & CCGTAAGTCGTCGCCATITTTA & & & & \\
\hline \multirow[t]{2}{*}{ mTOR } & CTGATGTCATTTATTGGCACAAA & 170 & 57 & 35 & [28] \\
\hline & CAGGGACTCAGAACACAAATGC & & & & \\
\hline \multirow[t]{2}{*}{ LC3 } & GGTCCAGTTGTGCCTTTATTGA & 153 & 59,5 & 35 & [28] \\
\hline & GTGTGTGGGTTGTGTACGTCG & & & & \\
\hline \multirow[t]{2}{*}{ p62 } & CTAGGCATCGAGGTTGACATT & 116 & 56 & 35 & [29] \\
\hline & CTTGGCTGAGTACCACTCTTATC & & & & \\
\hline \multirow[t]{2}{*}{ GAPDH } & GTTACCAGGGCTGCCTTCTC & 177 & 61 & 35 & [30] \\
\hline & GATGGTGATGGGTTTCCCGT & & & & \\
\hline
\end{tabular}


use and care of laboratory animals [20] and were approved by Research Ethics Committee of Universitas Padjadjaran with approval number, No 676/UN6.KEP/EC/2018.

\section{Treadmill training protocol}

Twenty male-wistar rats were divided into four groups: 3 groups of treadmill training (Low Intensity with treadmill speed $10 \mathrm{~m} /$ minute; Moderate Intensity with treadmill speed $20 \mathrm{~m} /$ minute, and High Intensity with treadmill speed $30 \mathrm{~m} /$ minute) and sedentary control ( $n=5$ for each group). This number of rats for each groups was calculated based on minimal sample calculation. The treadmill training intensities were defined based on lactate accumulation levels and followed previous study [21]. Rats were randomly allocated to 4 groups upon arrival, then acclimatized and habituated to environment for 2 weeks, followed by treadmill adaptation for another 2 weeks, then continued with treadmill training for 8 weeks, with frequency 5 days per week, and duration $30 \mathrm{~min}$ per day (Additional file 1: Figure S1). This study followed the protocol described by Vita et al., with a different detail purposes and scheme of the research [22].

At last training day, on 9 o'clock in the morning, in Animal Laboratorium of Universitas Padjadjaran, rats were sacrificed immediately after last training under inhaled isoflurane flow rate or concentration to $5 \%$ or greater, continued until 1 minute after breathing stopped [23]. Isoflurane was chosen as the anaesthetic drugs according to ethical approval as issued. Heart samples were collected; weighed; and dissected to separate left ventricle myocardium. Samples were snap frozen in liquid nitrogen and stored at $-80^{\circ} \mathrm{C}$ or fixed with PFA for histological studies.

\section{Histology}

Left ventricle myocardial tissues were fixed in buffered paraformaldehyde solution (4\%) and embedded in paraffin. Then, 2- $\mu \mathrm{m}$ thick sections were placed on adhesive slides and stained with hematoxylin-eosin. Samples were visualized using a Leica microscope (LEICA ICC50 HD) at $400 \mathrm{x}$ magnification using standard procedure. All imaging were performed with group identity blinded whereby at least 10 random images were obtained from each slide. Images were then quantified using imaging software (LAS EZ 2.0). The widths of randomly selected cardiomyocytes were measured from 100 LV cardiomyocytes to represent each sample.

Histologic examination of the LV muscles was reviewed by a single expert cardiac pathologist (RW) who was blinded to all other features of the samples characteristics. All samples were evaluated for the presence or absence of the following myocardial features: cardiomyocyte hypertrophy, myofiber disarray, and focal fibrosis. Hypertrophy was diagnosed if myocytes consistently had enlarged and hyperchromatic nuclei, and cell diameters greater than the diameters of 3 red blood cells/RBCs [24]. Myofiber disarray included cellular interlacing, whirling, or herringbone patterns [25]. Myocardium was evaluated for the presence or absence of focal fibrosis. In non-dilated hearts, myocyte diameter is directly proportional to the extent of hypertrophy. Therefore, hypertrophy was considered mild if myocyte overall diameters were 3-4 RBCs, moderate if they were 4-5 RBCs, and severe if they were $>5$ RBCs. Myofiber disarray was graded as mild if its extent was 1 to $25 \%$ of the myocardial area on the microscopic slide, moderate if 26 to $50 \%$, and severe if $>50 \%$. Focal fibrosis was determined to be absent if there was no focal fibrosis, mild if there was 0 to 5 , moderate if there was 6 to 10 , and severe if there was $>10$ focal fibrosis of the myocardial
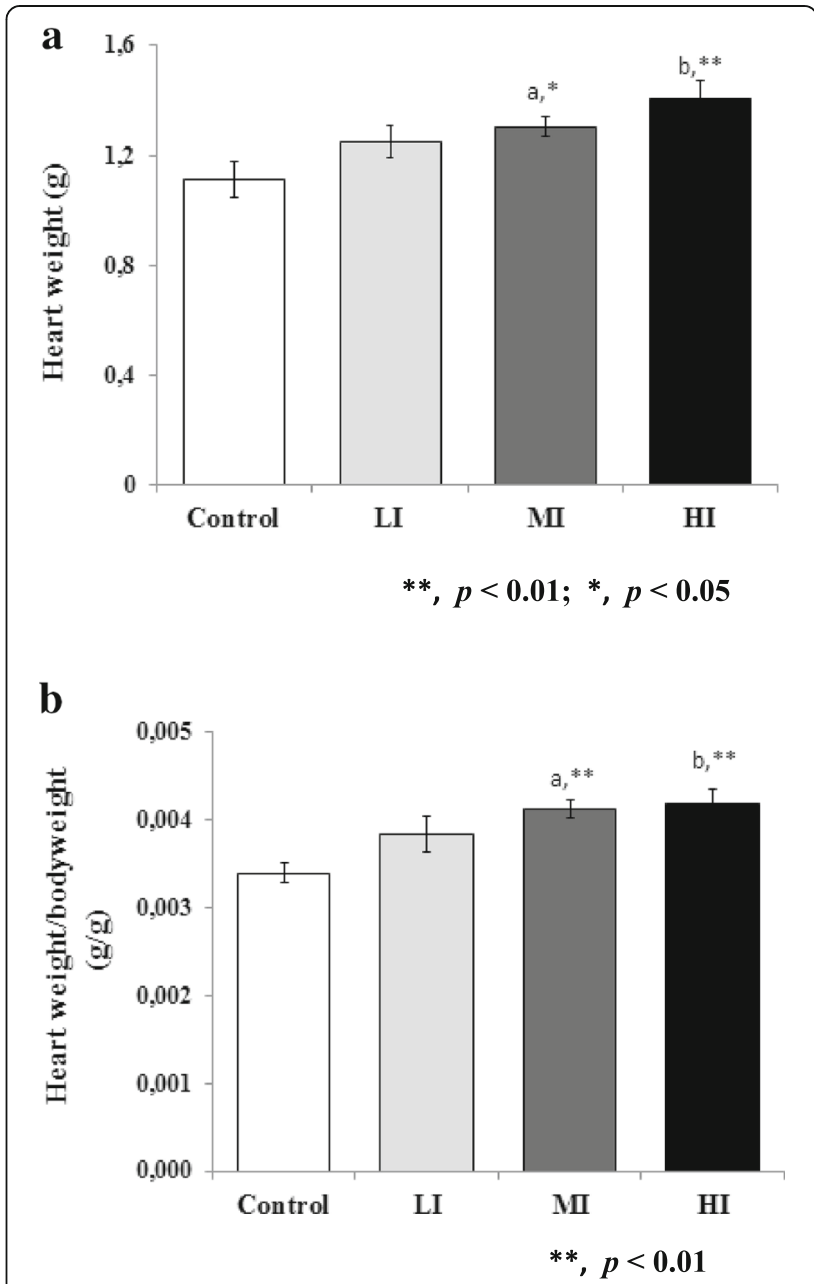

Fig. 1 Evaluation of Cardiac Hypertrophy After 8 Weeks of Treadmill Training with Different Intensity. a A significant increased of heart weight values were found in $\mathrm{MI}(\mathbf{a})$ and $\mathrm{HI}$ (b) compared to control. b Heart weight/body weight ratio showed even more significant increase in MI (a) and $\mathrm{HI}(\mathbf{b})$ compared to control. Data was presented as average mean \pm standard error of mean (SEM) with $p<0.05$ considered as significant $\left(^{*}\right)$ and $p<0.01$ considered as very significant $\left(^{* *}\right)$ 
area. This histology characterization was adaptated from another study with some modification [24].

\section{RNA extractions and semi-quantitative PCR}

RNA from left ventricle myocardial tissue were extracted using TRIsure reagent (Bioline, United Kingdom). Quantification of RNA extracted from the tissue were done using Multimode Microplate Reader at 268/280 nm absorbance spectrophotometry (M200 Pro, Tecan, Morrisville, NC). One Step RT PCR Kit (Bioline, United Kingdom) were used to conduct semiquantitative PCR, GAPDH were used as housekeeping gene. Electrophoresis Gels were visualized using BluePad Detection system and Image J were used for visualization and quantification of PCR band. Table 1 provided lists of primers sequences used in this study.

\section{Statistics}

The results of all individual values $(n=5)$ were presented in Additional file 2. SPSS 20.0 software was used for statistical analysis, the results were presented in Additional file 3. The presented results were mean \pm standard error of mean (mean \pm SEM). One Way ANOVA/Kruskal Wallis were

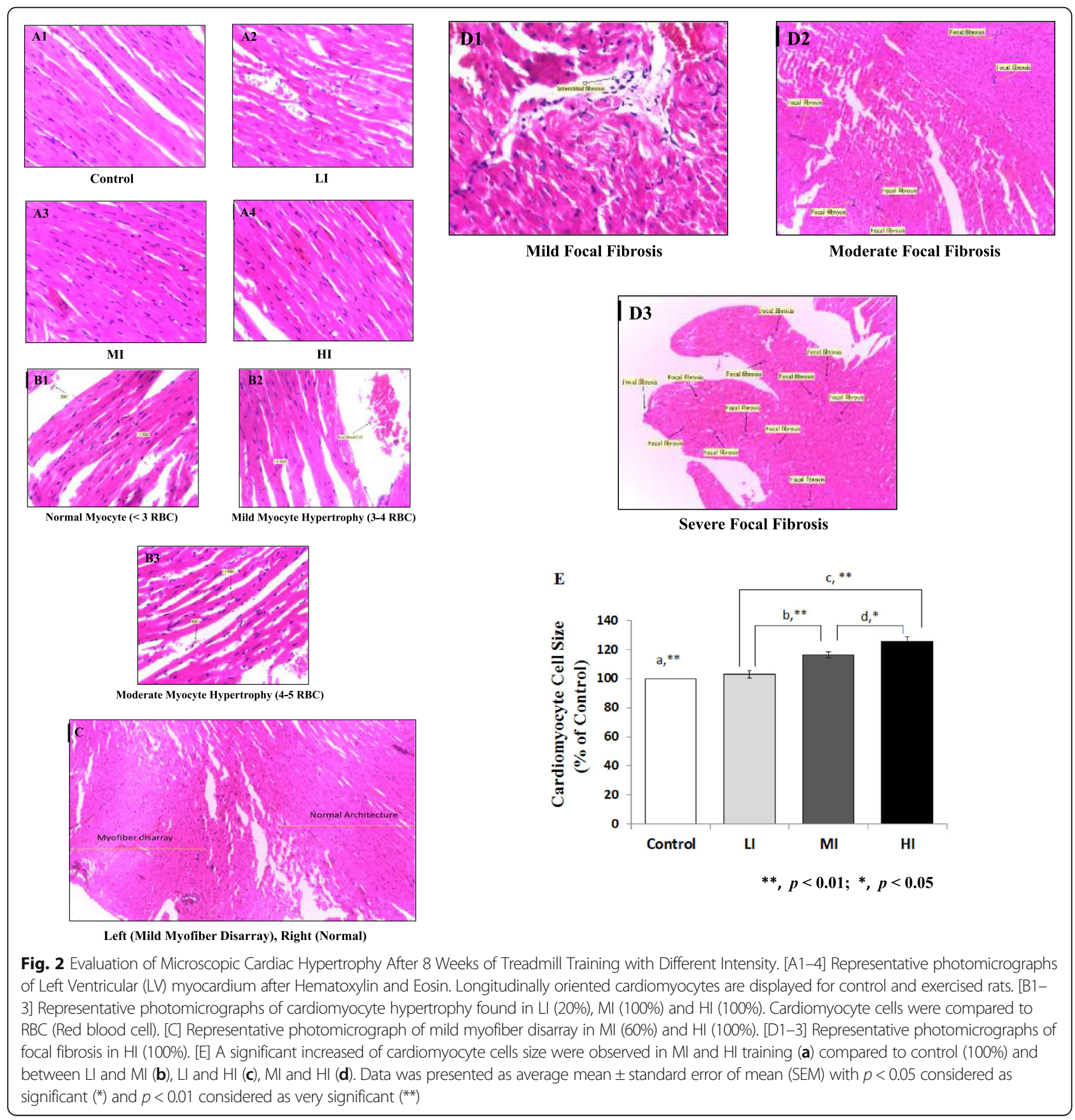


used to examine mean differences between groups with LSD post hoc test (for data with normal distribution) or Mann Whitney test (for data without normal distribution), with 95\% confidence interval $(p<0.05)$.

\section{Results}

Effects of training on heart weight and heart weight/body weight ratio

The rats of the four experimental groups had the similar initial body weights $(200 \pm 50 \mathrm{~g})$. The number of animals in each group included in each analysis is 5/5. Heart weights were recorded after termination and then compared to body weights to examine the ratio. We found a significant difference of heart weight in MI $(1.304 \pm 0.04)$ and $\mathrm{HI}(1.404 \pm 0.07)$, compared to control (1.112 \pm 0.07$)$, as showed in Fig. 1a. The heart weight to body weight ratio showed an even more significant increase in MI $(0.0041 \pm 0.00011)$ and $\mathrm{HI}(0.0042 \pm 0.00016)$ compared to control $(0.0034 \pm 0.00012)$ (Fig. $1 b)$, reflecting characteristics of cardiac hypertrophy.

\section{Effects of training on histology}

Training with different intensity resulted in a different histology characteristics presented in Fig. 2a-d and Table 2. For myocyte hypertrophy, we found none in control, $20 \%$ mild myocyte hypertrophy in LI, 40\% mild and 60\% moderate myocyte hypertrophy in MI, and $20 \%$ mild and $80 \%$

Table 2 Histologic Characterization of Cardiac Hypertrophy by Different Intensity

\begin{tabular}{lllll}
\hline Control & & & & \\
\hline & None & Mild & Moderate & Severe \\
\hline Myocyte hypertrophy & $5(100 \%)$ & 0 & 0 & 0 \\
Myofiber disarray & $5(100 \%)$ & 0 & 0 & 0 \\
Focal fibrosis & $5(100 \%)$ & 0 & 0 & 0 \\
Low-Intensity & & & & \\
& None & Mild & Moderate & Severe \\
Myocyte hypertrophy & $4(80 \%)$ & $1(20 \%)$ & 0 & 0 \\
Myofiber disarray & $5(100 \%)$ & 0 & 0 & 0 \\
Focal fibrosis & $5(100 \%)$ & 0 & 0 & 0 \\
Moderate-Intensity & & & & \\
Myocyte hypertrophy & 0 & $2(40 \%)$ & $3(60 \%)$ & 0 \\
Myofiber disarray & $2(40 \%)$ & $3(60 \%)$ & 0 & 0 \\
Focal fibrosis & $5(100 \%)$ & 0 & 0 & 0 \\
High-Intensity & & & & \\
& None & Mild & Moderate & Severe \\
Myocyte hypertrophy & 0 & $1(20 \%)$ & $4(80 \%)$ & 0 \\
Myofiber disarray & 0 & $5(100 \%)$ & 0 & 0 \\
Focal fibrosis & 0 & $1(20 \%)$ & $3(60 \%)$ & $1(20 \%)$ \\
\hline
\end{tabular}

moderate myocyte hypertrophy in HI. As for myofiber disarray, we found none in Control and LI, 60\% mild myofiber disarray in $\mathrm{MI}$, and $100 \%$ mild myofiber disarray in $\mathrm{HI}$. And for focal fibrosis, we found none in Control, LI, and MI, but $20 \%$ mild, $50 \%$ moderate, and $20 \%$ severe focal fibrosis in HI. We also found a significant increase in percentage cardiomyocyte cell size in MI $(116.4 \pm 2.04)$ and HI $(125.6 \pm 3.03)$ training compared to control (100\%) and LI $(103.1 \pm 2.38)$ (Fig. 2e).

\section{aMHC mRNA expressions in left ventricle myocardium of Wistar rats}

In order to confirm cardiac hypertrophy in training heart, we also examined $\alpha M H C$ gene expression using semiquantitative PCR. PCR bands of $\alpha \mathrm{MHC}$ were normalized using GAPDH. The result is presented in Fig. 3. In MI and $\mathrm{HI}$ groups, $\alpha \mathrm{MHC}$ gene expression were increased (MI 1.1 fold, $p<0.05$ and HI 1.2 fold, $p=0.076$ ) compared to control.

\section{PIK3CA and mTOR mRNA expressions in left ventricle myocardium of wistar rats}

We also examined PIK3CA and mTOR gene expressions in left ventricle myocardium of Wistar rats using semiquantitative PCR. PCR bands of PIK3A and mTOR were normalized using GAPDH. The result is presented in Fig. 4a-c. Training with low and moderate intensities significantly decreased PIK3CA gene expression (LI 0.8, MI $0.9, p<0.05)$. mTOR gene expression also significantly decreased (LI 0.9 fold, MI 0.9 fold $p<0.05$ ) compared to control, but interestingly, training with high intensity increased mTOR gene expression (HI 1.1, $p<0.05$ ).

\section{LC3 and p62 mRNA expressions in left ventricle myocardium of wistar rats}

We examined the autophagy related gene expression using semi-quantitative PCR. PCR bands of LC3 and p62 were normalized using GAPDH. The result is presented in Fig. 4a, d-e. Training significantly decreased expression of autophagy gene LC3 (LI 0.9 fold, MI 0.8 fold, HI 0.8 fold, $p<0.05)$ in left ventricle myocardium compared to control. On the other side, training significantly decreased p62 gene expression (LI 0.8 fold, MI 0.9 fold, $p<0.05$ ), and increased p62 gene expression (HI 1.1 fold, $p<0.05$ ).

\section{Discussion}

The heart contains multiple cell types, including myocytes (muscle cells), nonmyocytes (fibroblasts, endothelial cells, mast cells, leukocytes, vascular smooth muscle cells/mural cells), and the surrounding extracellular matrix. It is well accepted that cardiac myocytes represent $30-40 \%$ of the cell population in the adult rodent and human heart, so it represents $70-80 \%$ of the heart's volume. Hypertrophy of 
a

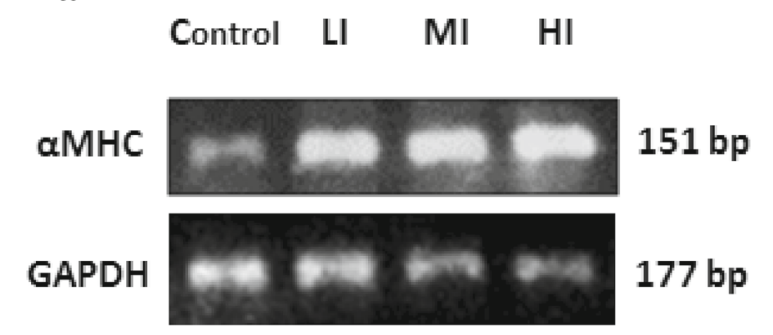

b

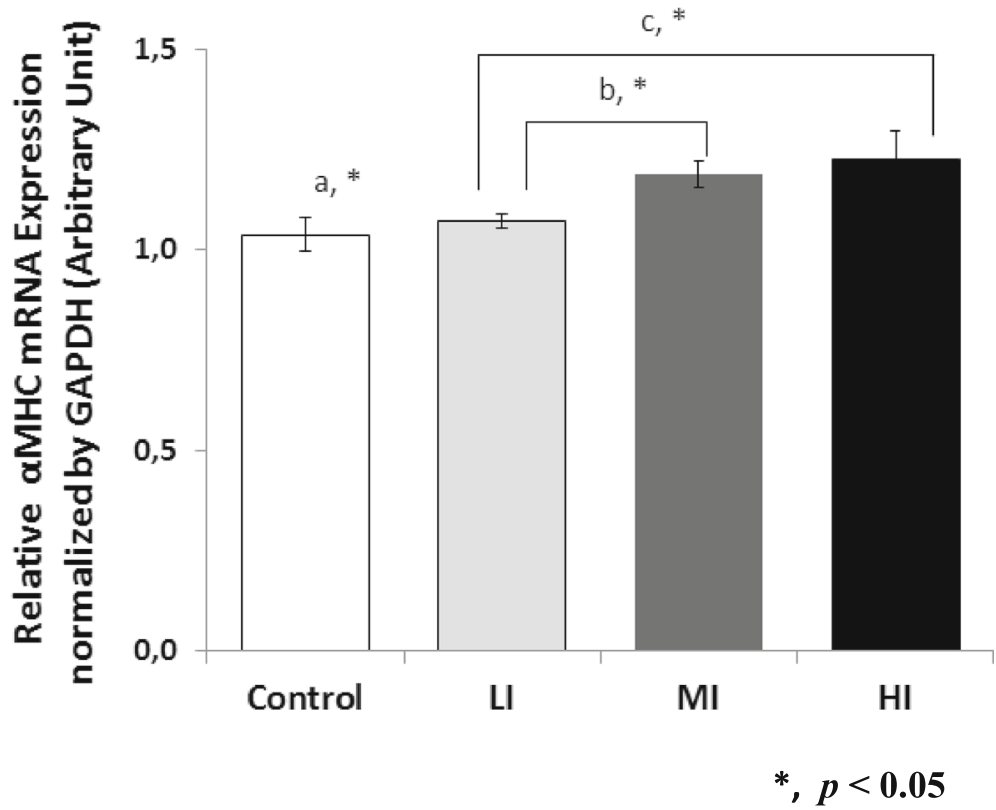

Fig. 3 aMHC mRNA Expression in Cardiac Muscles After 8 Weeks of Treadmill Training with Different Intensity. a 8 weeks of Treadmill Training with Different Intensity Stimulates aMHC mRNA Expression in Rat Cardiac Muscle (Left ventricle myocardium). b A significant increase of aMHC mRNA Expression were found in $\mathrm{Ml}$ compared to control (a), between $\mathrm{LI}$ and $\mathrm{MI}$ (b), and between $\mathrm{LI}$ and $\mathrm{HI}$ (c). aMHC mRNA expression in $\mathrm{HI}$ is increased with $p=0.076$, compared to control. Data was presented as average mean \pm standard error of mean (SEM) with $p<0.05$ considered as significant (*)

cardiac myocytes appears to be the predominant factor that contributes to heart enlargement as a response to chronic training $[9,31]$.

Different intensity of training may create different response of cardiac hypertrophy. In response to moderate training, cardiac hypertrophy occurs as an adaptive physiological response that is associated with normal or improved cardiac function [32, 33]. However, it is unavoided that endurance training have correlation with maladaptive responses in cardiac hypertrophy which is involving abnormal dynamic regulation of blood pressure, and histological rearrangement forming fibrotic tissue. Benito et al. had reported that fibrotic tissue in myocardial parenchyma as a consequence of regenerative and adaptive process can cause electrical impulse reentry lead to arrhythmogenicity [34].
In this present study, we found cardiac hypertrophy in MI and HI, supported by increased heart weight, heart weight/body weight ratio, histology, \% cardiomyocyte cell size and increased $\alpha M H C$ gene expression. Treadmill is one of animal modes that can induce physiological cardiac hypertrophy, measured both at the whole heart, ventricle, and individual cardiomyocyte level. This hypertrophy can be detected after 4 weeks of training, and reaches plateau after a few months if the training is sustained [35]. Our study also finds focal fibrosis in HI group, which may be associated with maladaptive training-induced cardiac remodeling. At least one animal study suggests that long-term, intensive endurance training (treadmill running for 16 weeks) is shown to be associated with fibrosis within the right ventricle. However in this study, the most marker of myocardial fibrosis 


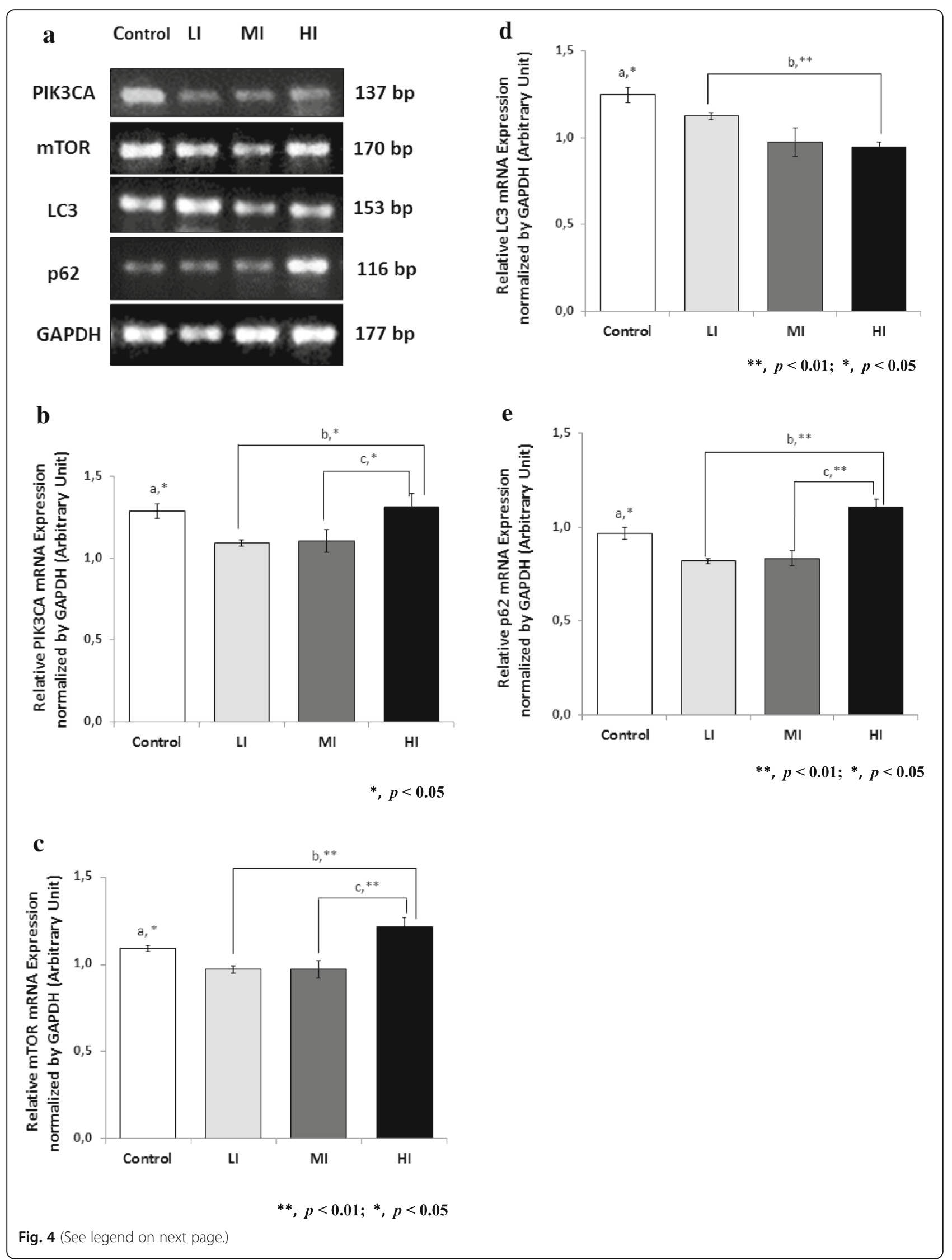


(See figure on previous page.)

Fig. 4 Autophagy Related mRNA Expression in Cardiac Muscles After 8 Weeks of Treadmill Training with Different Intensity. a 8 weeks of Treadmill Training with Different Intensity Modulates PIK3CA, mTOR, LC3, p62 mRNA Expression in Rat Cardiac Muscle (Left ventricle myocardium). b A significant decrease of PIK3CA mRNA Expression were found in $\mathrm{LI}$ and $\mathrm{Ml}$ compared to control (a), and between $\mathrm{LI}$ and $\mathrm{HI}$ (b), Ml and HI (c). c mTOR mRNA expression also significantly decreased in $\mathrm{LI}, \mathrm{MI}$ and increased in $\mathrm{HI}$ compared to control (a), between $\mathrm{LI}$ and $\mathrm{HI}$ (b) and MI and HI (c). d LC3 mRNA expression also significantly decreased in $\mathrm{LI}, \mathrm{Ml}$ and $\mathrm{HI}$ compared to control (a), and between $\mathrm{LI}$ and $\mathrm{HI}$ (b). e p62 mRNA expression also significantly decreased in $\mathrm{LI}, \mathrm{Ml}$ and increased in $\mathrm{HI}$ compared to control (a), between $\mathrm{LI}$ and $\mathrm{HI}$ (b) and $\mathrm{Ml}$ and $\mathrm{HI}$ (c). Data was presented as average mean \pm standard error of mean (SEM) with $p<0.05$ considered as significant $(*)$, and $p<0.01$ considered as very significant $\left(^{* *}\right)$

returned to baseline after discontinuation of training. This suggests that the fibrosis is of the reactive phenotype, which is reversible after detraining [33, 34].

Our study also shows an altered autophagy gene expression based on different intensity. LI and MI may increase autophagy gene expression, supported by decreased LC3, p62, mTOR, and PIK3CA relative ratio normalized by GAPDH. However, HI may decrease autophagy, supported by decreased LC3 and increased p62, mTOR relative ratio normalized by GAPDH. Recent studies have shown that endurance training can enhance autophagy in cardiac muscles [16, 36]. Increased autophagy in LI and decreased autophagy in $\mathrm{HI}$ may be associated with a decrease and increase of protein synthesis that correlates with cardiac hypertrophy.

The best signaling cascades responsible for mediating physiological cardiac hypertrophy is IGF1-PI3KCA/ PI3K(p110 $\alpha$ )-Akt pathway. mTOR is a downstream pathway of IGF1-PIK3CA that has long been considered to be a potent autophagy regulator, as inhibition or activation of mTOR regulates autophagy [37]. In this study, we found a decrease of mTOR and PIK3CA gene expression in LI and MI, suggested autophagy may be increased in cardiac muscle as a result of traininginduced adaptation. Interestingly, we also found cardiac hypertrophy in MI training, this suggest that cardiac hypertrophy may occur from other pathway, like gp130/ JAK/STAT pathway, but a future study is needed to confirm this hypothesis.

The limitation of this study is that we did not examine cardiac function and collagen deposition in left ventricle. There are also possibilities that the physiological cardiac hypertrophy after training could be affected by other factors, such as hormonal [38], genetic [39], or other metabolic factors [40]. This study has been demonstrated the effect of different intensity of treadmill training on cardiac hypertrophy of male wistar rats, and may not be applicable in humans. Further study has to be carried out to know the effect of different treadmill intensity on cardiac hypertrophy in humans, in order to determine how much training is optimal for cardiovascular benefit, which is correlated with cardiac physiological adaptation after training with autophagy regulation involvement $[8,9]$.

\section{Conclusion}

In summary, different training intensity might stimulate different process of cardiac hypertrophy that correlates with autophagy. LI training may increase autophagy related gene expression, but not inducing cardiac hypertrophy. MI training may induce cardiac hypertrophy with increased autophagy related gene expression, while HI training may induce cardiac hypertrophy with decreased autophagy related gene expression.

\section{Additional files}

Additional file 1: Figure S1. Experimental Design of the Research. Animals were randomly allocated to 4 groups upon arrival. Three treadmill training intensities (Low-Intensity/LI, Moderate-Intensity/MI, and High-Intensity/HI) and one group without treadmill training/Control, were compared. (DOCX 44 kb)

Additional file 2: Individual Data of The Research. (DOCX $27 \mathrm{~kb}$ )

Additional file 3: Statistical Results of The Research. (DOCX 104 kb)

\section{Abbreviations}

HI: High Intensity; LI: Low Intensity; MI: Moderate Intensity

\section{Acknowledgments}

The authors would like to thank Susianti, Deni and Nurul Ihsani for technical assistance during experiments. We would also like to thank dr. Hanna, dr. Nova, dr. Cherry, dr. Teresa, Dr. Anindita, dr. Yuni, drh. Okta, Septo, Regia, Gina, Debby, Julidea and Azis for assisting in animal treatment.

\section{Authors' contributions}

JWG and RL designed, planned the project and analyzed the data. VMT, US and IS performed data analysis, and completed the manuscript. RW made the histological slides, completed acquisition, analysis, and interpretation of data associated with the slides. All authors read and approved the final manuscript.

\section{Funding}

This study was fully supported by LPDP/Lembaga Pengelola Dana Pendidikan (S-494/LPDP.3/2018) to JWG. The role of the funder are providing reagents and materials required for the research, and also covering publication fee.

\section{Availability of data and materials}

The datasets used and/or analysed during the current study are available from the corresponding author on reasonable request.

Ethics approval and consent to participate

This protocol were approved by Research Ethics Committee of Universitas Padjadjaran No 676/UN6.KEP/EC/2018.

\section{Consent for publication}

Not applicable.

Competing interests

The authors declare that they have no competing interest. 


\section{Author details}

'Department of Physiology, Faculty of Medicine, Maranatha Christian University, Bandung, Indonesia. ${ }^{2}$ Physiology Division, Department of Biomedical Science, Faculty of Medicine, Universitas Padjadjaran, Bandung, Indonesia. ${ }^{3}$ Division of Biological Activity, Central Laboratory, Universitas Padjadjaran, Bandung, Indonesia. ${ }^{4}$ Center of Excellence in Higher Education for Pharmaceutical Care Innovation, Universitas Padjadjaran, Bandung, Indonesia. ${ }^{5}$ Department of Anatomy Pathology, Faculty of Medicine, Maranatha Christian University, Bandung, Indonesia. ${ }^{6}$ Department of Chemistry, Faculty of Mathematics and Natural Sciences, Universitas Padjadjaran, Bandung, Indonesia.

Received: 10 March 2019 Accepted: 29 May 2019 Published online: 10 June 2019

\section{References}

1. Tortora GJ, Derrickson B. Principles of anatomy and physiology. 14th ed. United States of America: John Wiley \& Sons, Inc.; 2014

2. Weeks KL, McMullen JR. The athlete's heart vs. the failing heart: can signaling explain the two distinct outcomes? Physiology (Bethesda). 2011; 26:97-105

3. Ellison GM, Waring CD, Vicinanza C, Torella D. Physiological cardiac Remodelling in response to endurance exercise training: cellular and molecular mechanisms. Heart. 2012:98:5-10.

4. Bernardo BC, Weeks KL, Pretorius L, McMullen JR. Molecular distinction between physiological and pathological cardiac hypertrophy: experimental findings and therapeutic strategies. Pharmacol Ther. 2010;128:191-227.

5. Maron BJ, Pelliccia A. The heart of trained athletes : cardiac remodeling and the risks of sports, including Suddent death. Circulation. 2006;114:1633-44.

6. Maron BJ, Pelliccia A, Spataro A, Granata M. Reduction in left ventricular wall thickness after deconditioning in highly trained Olympic athletes. $\mathrm{Br}$ Heart J. 1993;69:125-8

7. Pelliccia A, Maron BJ, De Luca R, Di Paolo FM, Spataro A, Culasso F. Remodeling of left ventricular hypertrophy in elite athletes after long-term deconditioning. Circulation. 2002;105:944-9.

8. Nystoriak MA, Bhatnagar A. Cardiovascular effects and benefits of exercise. Frontiers in Cardiovascular Medicine. 2018:5:135.

9. Bernardo BC, ], Ooi JYY, Weeks KL, Patterson NL, McMullen JR. Understanding key mechanisms of exercise-induced cardiac protection to mitigate disease: current knowledge and emerging concepts. Physiol Rev 2018:98:419-475

10. Lee $\mathrm{CH}$, Inoki K, Guan KL. mTOR pathway as a target in tissue hypertrophy Annu Rev Pharmacol Toxicol. 2007;47:443-67.

11. Saxton RA, Sabatini DM. mTOR signaling in growth, metabolism, and disease. Cell. 2017;168:960-76.

12. Sciarretta S, Forte M, Frati G, Sadoshima J. New insights into the role of mTOR signaling in the cardiovascular system. Circ Res. 2018;122:489-505.

13. Mizushima N, Komatsu M. Autophagy: renovation of cells and tissues. Cell. 2011;147:728-41

14. Hamacher-Brady A, Brady NR, Gottlieb RA. Enhancing macroautophagy protects against ischemia/reperfusion injury in cardiac myocytes. J Biol Chem. 2006;281:29776-87.

15. Xie M, Kong Y, Tan W, May H, Battiprolu PK, Pedrozo Z, et al. Histone deacetylase inhibition blunts ischemia/reperfusion injury by inducing cardiomyocyte autophagy. Circulation. 2014;129:1139-51.

16. He C, Bassik MC, Moresi V, Sun K, Wei Y, Zou Z, et al. Exercise-induced BCL2regulated autophagy is required for muscle glucose homeostasis. Nature. 2012;481:511-5

17. Lee Y, Kang EB, Kwon I, Cosio-Lima L, Cavnar P, Javan GT. Cardiac Kinetophagy coincides with activation of anabolic signaling. Med Sci Sports Exerc. 2016:48:219-26.

18. Ogura $Y$, lemitsu M, Naito $H$, Kakigi $R$, Kakehashi $C$, Maeda S, et al. Single bout of running exercise changes LC3-II expression in rat cardiac muscle. Biochem Biophys Res Commun. 2011;414:756-60.

19. Fiuza-Luces C, Delmiro A, Soares-Miranda L, González-Murillo Á, MartínezPalacios J, Ramírez M, et al. Exercise training can induce cardiac autophagy at end-stage chronic conditions: insights from a graft-versus-host-disease mouse model. Brain Behav Immun. 2014;39:56-60.

20. Council NR. Guide for the Care and Use of Laboratory Animals. 8th edition ed. Washington (DC): National Academies Press (US); 2011. p. 246.
21. Lesmana R, Iwasaki T, lizuka Y, Amano I, Shimokawa N, Koibuchi N. The change in thyroid hormone signaling by altered training intensity in male rat skeletal muscle. Endocr J. 2016;63:727-38.

22. Tarawan VM, Gunadi JW, Setiawan LR, Goenawan H, Meilina DE, et al. Alteration of autophagy gene expression by different intensity of exercise in gastrocnemius and soleus muscles of Wistar rats. J Sports Sci Med. 2019;18:146-54.

23. Association AVM. AVMA guidelines for the euthanasia of animals: 2013 Edition; 2013. p. 1-102.

24. McLeod CJ, Bos JM, Theis JL, Edwards WD, Gersh BJ, Ommen SR, et al. Histologic characterization of hypertrophic cardiomyopathy with and without myofilament mutations. Am Heart J. 2009:158:799-805.

25. Maron BJ, Wolfson JK, Roberts WC. Relation between extent of cardiac muscle cell disorganization and left ventricular wall thickness in hypertrophic cardiomyopathy. Am J Cardiol. 1992;70:785-90.

26. Grabner A, Amaral AP, Schramm K, Singh S, Sloan A, Yanucil C, et al. Activation of cardiac fibroblast growth factor receptor 4 causes left ventricular hypertrophy. Cell Metab. 2015;22:1020-32

27. Krusen M, Keyhani-Nejad F, Isken F, Nitz B, Kretschmer A, Reischl E, et al. High-fat diet during mouse pregnancy and lactation targets GIP-regulated metabolic pathways in adult male offspring. Diabetes. 2016;65:574-84.

28. Yin P, Wan C, He S, Xu X, Liu M, Song S, et al. Transport stress causes damage in rats' liver and triggers liver autophagy. Bio Technology : An Indian Journal. 2013;8:1561-6.

29. Kowalik MA, Perra A, Ledda-Columbano GM, Ippolito G, Piacentini M, Columbano A, et al. Induction of autophagy promotes the growth of early preneoplastic rat liver nodules. Oncotarget. 2016;7:5788-99.

30. Wang K, Wang F, Bao JP, Xie ZY, Chen L, Zhou BY, et al. Tumor necrosis factor a modulates sodium-activated potassium channel SLICK in rat dorsal horn neurons via p38 MAPK activation pathway. J Pain Res. 2017;10:1265-71.

31. Pinto AR, llinykh A, Ivey MJ, Kuwabara JT, D'Antoni ML, Debuque R, et al. Revisiting cardiac cellular composition. Circ Res. 2016;118:400-9.

32. Boström P, Mann N, Wu J, Quintero PA, Plovie ER, Panáková D, et al. C/EBPß controls exercise-induced cardiac growth and protects against pathological cardiac remodeling. Cell. 2010;143:1072-83.

33. Bernardo BC, McMullen JR. Molecular aspects of exercise-induced cardiac remodeling. Cardiol Clin. 2016;34:515-30.

34. Benito B, Gay-Jordi G, Serrano-Mollar A, Guasch E, Shi Y, Tardif JC, et al. Cardiac arrhythmogenic remodeling in a rat model of long-term intensive exercise training. Circulation. 2011;123:13-22.

35. Wang $Y$, Wisloff $U$, Kemi OJ. Animal models in the study of exercise-induced cardiac hypertrophy. Physiol Res. 2010;59:633-44.

36. Lee Y, Kwon I, Jang Y, Song W, Cosio-Lima LM, Roltsch MH. Potential signaling pathways of acute endurance exercise-induced cardiac autophagy and mitophagy and its possible role in cardioprotection. The Journal of Physiological Science: JPS. 2017;67:639-54

37. Kim J, Kundu M, Viollet B, Guan KL. AMPK and mTOR regulate autophagy through direct phosphorylation of Ulk1. Nat Cell Biol. 2011;13:132-41.

38. Vasan RS, Larson MG, Levy D, Evans JC, Benjamin EJ. Distribution and categorization of echocardiographic measurements in relation to reference limits: the Framingham heart study: formulation of a height- and sex-specific classification and its prospective validation. Circulation. 1997;96:1863-73.

39. An P, Borecki IB, Rankinen T, Després JP, Leon AS, Skinner JS, et al. Evidence of major genes for plasma HDL, LDL cholesterol and triglyceride levels at baseline and in response to 20 weeks of endurance training: the HERITAGE family study. International Journals of Sport Medicine. 2005:26:414-9.

40. Vega RB, Konhilas JP, Kelly DP, Leinwand LA. Molecular mechanisms underlying cardiac adaptation to exercise. Cell Metab. 2017:25:1012-26.

\section{Publisher's Note}

Springer Nature remains neutral with regard to jurisdictional claims in published maps and institutional affiliations. 